\title{
PENGARUH SERVANT LEADERSHIP TERHADAP KINERJA KARYAWAN BAGIAN PROSESING DI KANTOR MAIL PROCESSING CENTRE BANDUNG
}

\author{
Muji Rahayu \\ Program Studi Manajemen \\ STIE-STAN IM, Jl. Jakarta No.79 Bandung
}

\begin{abstract}
ABSTRAK
Penelitian ini bertujuan untuk mengkaji pengaruh servant leadership terhadap kinerja karyawan bagian prosesing di Kantor Mail Processing Centre Bandung. Variabel terikat dalam penelitian ini adalah kinerja karyawan bagian prosesing. Sedangkan servant leadership sebagai variabel bebas. Responden dalam penelitian ini sebanyak 50 karyawan bagian mail prosesing. Metode yang digunakan adalah metode analisis deskriptif. Pengolahan data menggunakan analisis regresi. Hasil penelitian menyatakan bahwa korelasi antara servant leadership dengan kinerja karyawan termasuk dalam kategori tinggi. Hasil uji signifikansi menunjukkan bahwa servant leadership berpengaruh secara positif dan signifikan terhadap kinerja karyawan bagian prosesing di Kantor Mail Processing Centre Bandung.
\end{abstract}

Kata kunci : Servant Leadership, Kinerja Karyawan

\section{PENDAHULUAN}

Makin meningkatnya kebutuhan masyarakat di bidang pelayanan jasa pengiriman saat ini, mendorong munculnya ribuan perusahaan yang bergerak di bidang layanan ini. Konsumen makin cerdas dalam memilih dan menggunakan jasa pengiriman. Begitu banyak perusahaan yang menyediakan layanan yang sama sehingga masing-masing perusahaan berusaha menyediakan layanan terbaiknya.

Agar dapat menjadi perusahaan jasa pengiriman yang terpercaya dan tetap diminati oleh konsumen diperlukan sumber daya manusia handal dan pelayanan yang terbaik sesuai dengan harapan konsumen. Pelayanan dipandang sebagai bagian penting dari kinerja individu dalam upaya mencapai tujuan perusahaan.

Kinerja adalah hasil kerja yang dicapai seseorang atau sekelompok orang dalam suatu organisasi baik secara kuantitatif maupun kualitatif sesuai dengan kewenangan dan tugas tanggung jawab masing-masing dalam upaya mencapai tujuan organisasi (Moeheriono,2009:61). Banyak faktor yang dipandang dapat mempengaruhi kinerja diantaranya adalah kepemimpinan. Moeheriono (2014)

Yukl (2005:4) mendefinisikan kepemimpinan adalah kemampuan individu untuk mempengaruhi, memotivasi, dan membuat orang lain mampu memberikan kontibusinya 
demi efektivitas dan keberhasilan organisasi.. Ada banyak tipe dan gaya kepemimpinan yang diterapkan, salah satunya adalah servant leadership. (Northouse ,2013:5). Greenleaf (1970) mengemukakan bahwa kepemimpinan yang melayani (servant leadership) dimulai dengan perasaan alamiah bahwa kita ingin melayani lebih dulu, lalu pilihan yang disadari membawa seseorang berharap untuk memimpin. Servant leadership adalah pendekatan yang berfokus pada kepemimpinan dari sudut pandang pemimpin dan perilakunya, mengutamakan pengikut, perhatian pada masalah mereka, empati dengan mereka dan membantu mengembangkan kapasitas pribadinya secara penuh.

Terdapat beberapa hasil penelitian mengenai pengaruh terhadap kinerja, yaitu penelitian yang dilakukan oleh Harwiki (2013) yang menemukan bahwa servant leadership berpengaruh positif dan signifikan terhadap kinerja,. kinerja. Hasil penelitian ini sejalan dengan penelitian yamg dilakukan Awan et al., (2012) yang menyatakan bahwa servant leadership berpengaruh positif terhadap kinerja karyawan. Namun berbeda dengan Lisbijanto dan Budiyanto (2014) yang menemukan bahwa servant leadership tidak berpengaruh positif dan signifikan terhadap kinerja.

\section{REVIEW LITERATUR DAN PENGEMBANGAN HIPOTESIS}

Greenleaf menekankan bahwa servant leadership memiliki tanggung jawab sosial untuk peduli dengan orang-orang tak berpunya dan mereka yang tidak beruntung. Dengan menjadi pemimpin yang melayani seorang pemimpin menggunakan kekuatan dan kendali institusional yang lebih sedikit sambil menggeser otoritas tersebut kepada mereka yang dipimpin. Greenleaf menambahkan bahwa servant leadership menghargai komunitas karena hal itu memberi peluang bagi individu untuk langsung mengalami saling ketergantungan, penghargaan, kepercayaan, dan pertumbuhan individual. Ketika banyak pemimpin di dalam organisasi mengadopsi servant leadership, maka suatu budaya untuk saling melayani di dalam dan di luar organisasi akan tercipta. Liden dalam Northouse (213:220). Sementara itu Graham dalam Northouse (2013:220) mengemukakan bahwa servant leadership meluas ke tindakan untuk melayani masyarakat "yang tidak berpunya". Memperkuat definisi yang telah dikemukakan sebelumnya Petterson dalam Mc Shane (2018:344) menjelaskan bahwa servant leadership adalah pemimpin yang melayani pengikut dengan cara menolong pengikut 
memenuhi kebutuhannya, melatih, membantu, menjadi fasilitator bagi pengembangan diri pengikut.

Bagi individu, Servant leadership berfokus langsung pada pengakuan kontribusi pengikut dan membantu mereka menyadari potensinya. Hasil dari servant leadership menurut Meuser et al., dalam Northouse (2013:218) adalah pengikut menjadi lebih efektif dalam menyelesaikan pekerjaan mereka dan memenuhi deskripsi jabatan mereka.

Bagi Organisasi, servant leadership mempengaruhi cara tim organisasi berfungsi. Hu dan Liden dalam Northouse (2013:218) mendapati bahwa servant leadership meningkatkan keefektifan tim dengan meningkatkan keyakinan pengikut, bahwa mereka bisa menjadi efektif sebagai kelompok kerja. Memiliki dampak yang positif bagi masyarakat. Di dalam konsep servant leadership Greenleaf tidak membatasi proses sebagai sesuatu yang dimaksudkan untuk mengubah masyarakat secara langsung. Tetapi justru menggambarkan pemimpin yang menjadi pelayan dulu mendengarkan orang lain serta membantu mereka tumbuh. Sebagai hasilnya organisasi mereka lebih sehat, dan akhirnya menguntungkan bagi masyarakat. Dalam cara ini, hasil jangka panjang dengan mengutamakan orang lain mencakup perubahan sosial yang positif, serta ikut membantu masyarakat untuk tumbuh.

Kinerja adalah hasil kerja seorang pekerja, sebuah proses manajemen atau suatu organisasi secara keseluruhan, dimana hasil kerja tersebut harus dapat ditunjukkan buktinya secara konkrit dan dapat diukur (dibandingkan dengan standar yang telah ditentukan). Sedarmayanti (2014:240). Campbell dalam Sudarmanto (2014:9) menyatakan bahwa kinerja adalah tindakan yang relevan dengan tujuan perusahaan. Selanjutnya Suwatno dan Priansa (2014:196) kinerja adalah hasil yang dicapai sesorang menurut ukuran yang berlaku, dalam kurun waktu tertentu, berkenaan dengan pekerjaan serta perilaku dan tindakannya.

Penelitian - penelitian terdahulu menyatakan bahwa servant leadership memiliki pengaruh yang positif dan signifikan terhadap kinerja karyawan. Diantaranya penelitian yang dilakukan oleh Harwiki (2013) dan Koesmono (2014). Berbeda dengan hasil penelitian tersebut, Lisbijanto dan Budiyanto (2014) menemukan bahwa servant leadership tidak berpengaruh positif terhadap kinerja karyawan.

H1 : Servant Leadership berpengaruh positif terhadap kinerja karyawan 


\section{METODE PENELITIAN}

Objek dalam penelitian ini meliputi faktor kinerja karyawan berperan sebagai variabel dependen, servant leadership berperan sebagai variabel independen. Unit analisis penelitian ini adalah karyawan dari bagian prosesing Kantor Mail Processing Centre Bandung. Jumlah sanpel sebanyak 50 subyek, dengan menggunakan teknik non probabiliy sampling. Instrumen penelitian untuk mengumpulkan data dengan menggunakan kuesioner. Metode yang dipakai dalam penelitian ini adalah metode diskriptif dengan pendekatan survey. Siregar (2013:7) menjelaskan bahwa penelitian diskriptif adalah penelitian yang digunakan untuk mengetahui nilai variabel tanpa membuat perbandingan. Kuesioner servant leadership sebanyak 13 item diadaptasi dari Northouse (2013) dan kinerja sebanyak 10 item diadaptasi dari Mas'ud (2004). Kuesioner menggunakan skala Likert mulai dari angka 1 ( Sangat Tidak Setuju) sampai angka 5 ( Sangat Setuju). Hasil penelitian dijelaskan dalam tabel, model dan narasi yang bersifat menjelaskan data.

\section{TEMUAN - TEMUAN}

\subsection{Profil Responden}

TABEL 1. Tabel Profil Responden

\begin{tabular}{|c|c|c|c|}
\hline Profil & Mayoritas & Jumlah & $\%$ \\
\hline Jenis Kelamin & Laki -laki & 43 & 86 \\
\hline Usia & 40 -50 tahun & 31 & 62 \\
\hline Pendidikan Terakhir & SLTA/Sederajat & 40 & 80 \\
\hline Status Marital & Menikah & 49 & 98 \\
\hline Masa Kerja & Lebih dari 6 tahun & 48 & 96 \\
\hline
\end{tabular}

Profil responden menunjukkan bahwa mayoritas jenis kelamin laki-laki usia antara 40 - 50 tahun, pendidikan terakhir adalah SLTA/ Sederajat, staus marital adalah menikah dengan masa kerja lebih dari 6 tahun.

\subsection{Validitas dan Reliabilitas}

TABEL 2. Uji Validitas

\begin{tabular}{|c|l|c|c|}
\hline No. & \multicolumn{1}{|c|}{ Variabel } & Rentang Korelasi & Keterangan \\
\hline 1. & Servant leadership & $0,312-0,832$ & Valid \\
\hline 2. & Kinerja & $0,371-0,840$ & Valid \\
\hline
\end{tabular}


Tabel 2 menunjukkan niilai koefisien korelasi product moment tiap item dari seluruh pernyataan variabel servant leadership dan kinerja yang diujikan, menunjukkan bahwa seluruh item dari variabel-varibel tersebut dinyatakan valid dengan rentang nilai korelasi untuk variabel servant leadership anatara 0,312-0,832, dan variabel kinerja antara $0,371-0,840$.

TABEL 3. Uji Reliabilitas

\begin{tabular}{|c|l|c|c|}
\hline No. & \multicolumn{1}{|c|}{ Variabel } & Cronbach's Alpha & Keterangan \\
\hline 1. & Servant leadership & 0,903 & Reliabel \\
\hline 2. & Kinerja & 0,908 & Reliabel \\
\hline
\end{tabular}

Tabel 3 menunjukkan hasil uji reliabilitas dengan teknik cronbach alpha variabel servant leadership memperoleh nilai 0,903 dan kinerja memperoleh nilai 0,908 oleh karena itu dapat dinyatakan bahwa data memenuhi kriteria reliabel

\subsection{Tanggapan Responden Terhadap Servant Leadership, dan Kinerja.}

TABEL 4. Resume Servant Leadership

\begin{tabular}{|c|c|c|}
\hline Pernyataan & $\begin{array}{c}\text { Skor } \\
\text { Rata - rata }\end{array}$ & Kriteria \\
\hline 1. Kepedulian kebahagiaan karyawan & 168 & Tinggi \\
\hline 2. Menekankan kontribusi kepada perusahaan & 184 & Tinggi \\
\hline 3. Membantu karyawan dalam komunitasnya & 204 & $\begin{array}{l}\text { Sangat } \\
\text { Tinggi }\end{array}$ \\
\hline 4. Mengetahui yang terkait pekerjaan & 184 & Tinggi \\
\hline 5. Mampu mengatasi masalah & 203 & $\begin{array}{l}\text { Sangat } \\
\text { Tinggi }\end{array}$ \\
\hline 6. Memberi kesempatan membuat keputusan penting & 203 & $\begin{array}{l}\text { Sangat } \\
\text { Tinggi }\end{array}$ \\
\hline 7. Mendorong menangani keputusan sendiri & 197 & Tinggi \\
\hline 8. Memprioritaskan pengembangan karier karyawan & 203 & $\begin{array}{l}\text { Sangat } \\
\text { Tinggi }\end{array}$ \\
\hline 9. Memastikan karyawan mencapai tujuan & 202 & $\begin{array}{l}\text { Sangat } \\
\text { Tinggi }\end{array}$ \\
\hline 10. Peduli terhadap kesuksesan karyawan & 199 & Tinggi \\
\hline 11. Mengutamakan kepentingan karyawan & 197 & Tinggi \\
\hline 12. Memiliki standar etika tinggi & 185 & Tinggi \\
\hline 13. . Selalu jujur & 173 & Tinggi \\
\hline & 192,5 & Tinggi \\
\hline
\end{tabular}

Untuk variabel servant leadership mencapai skor rata-rata 192,5 masuk dalam ketegori tinggi, artinya servant ledearship yang diterapkan di kantor Mail Processing 
Centre Bandung sudah baik. Namun masih perlu ditingkatkan untuk item pernyataan yang memperoleh skor terendah 168 yaitu pada item kepedulian terhadap kebahagiaan karyawan.

TABEL 5. Resume Kinerja

\begin{tabular}{|l|c|c|}
\hline \multicolumn{1}{|c|}{ Pernyataan } & $\begin{array}{c}\text { Skor } \\
\text { Rata -rata }\end{array}$ & Kriteria \\
\hline 1. Kuantitas kerja melebihi karyawan lain & 200 & $\begin{array}{l}\text { Sangat } \\
\text { Tinggi }\end{array}$ \\
\hline 2. Kualitas kerja lebih baik dari karyawan lain & 197 & Tinggi \\
\hline 3. Efisiensi karyawan melebihi karyawan lain & 183 & $\begin{array}{l}\text { Sangat } \\
\text { Tinggi }\end{array}$ \\
\hline 4. Kualitas melebihi standar & 201 & $\begin{array}{l}\text { Sangat } \\
\text { Tinggi }\end{array}$ \\
\hline 5. Berusaha lebih keras & 200 & $\begin{array}{l}\text { Sangat } \\
\text { Tinggi }\end{array}$ \\
\hline 6. Kemampuan pekerjaan utama baik & 201 & $\begin{array}{l}\text { Sangat } \\
\text { Tinggi }\end{array}$ \\
\hline 7. Melaksanakan pekerjaan tepat waktu & 205 & $\begin{array}{l}\text { Sangat } \\
\text { Tinggi }\end{array}$ \\
\hline 8. Pengetahuan pekerjaan utama baik & 203 & $\begin{array}{l}\text { Sangat } \\
\text { Tinggi }\end{array}$ \\
\hline 9. Kreativitas pekerjaan utama baik. & 207 & $\begin{array}{l}\text { Sangat } \\
\text { Tinggi }\end{array}$ \\
\hline 10. Sesuai prosedur dan kebijakan & 205 & $\begin{array}{l}\text { Sangat } \\
\text { Tinggi }\end{array}$ \\
\hline & 200,2 & $\begin{array}{l}\text { Sangat } \\
\text { Tinggi }\end{array}$ \\
\hline
\end{tabular}

Secara umum kinerja memiliki skor 200,2 dari 10 pernyataan dan dapat dikategorikan baik. 4 item pernyataan masuk dalam kriteria sangat baik. Namun masih perlu ditingkatkan untuk item dengan skor terendah 183, yaitu pada pernyataan Efisiensi melebihi karyawan yang lain 


\subsection{Korelasi Antar Variabel}

TABEL 6. Korelasi Antar Variabel

\begin{tabular}{|c|c|c|c|}
\hline & & $\begin{array}{c}\text { Servant } \\
\text { leadership }\end{array}$ & Kinerja \\
\hline \multirow{4}{*}{ Servant leadership } & Pearson Correlation & 1 & $.918^{* *}$ \\
\hline & Sig. (2-tailed) & & .000 \\
\hline & $\mathrm{N}$ & 50 & 50 \\
\hline & Pearson Correlation & $.918^{* *}$ & 1 \\
\hline \multirow[t]{2}{*}{ Kinerja } & Sig. (2-tailed) & .000 & \\
\hline & $\mathrm{N}$ & 50 & 50 \\
\hline
\end{tabular}

Berdasarkan hasil perhitungan pada tabel tersebut diatas, dapat disimpulkan bahwa besarnya koefisien servant leadership dan kinerja adalah 0,918 . Hal ini berarti bahwa servant leadership dan kinerja mempunyai hubungan yang positif serta nilai signifikansi 0,000 lebih kecil dari 0,05, yang berarti keduanya memiliki hubungan yang signifikan.

\subsection{Pengujian Hipotesis}

TABEL 7. Out Put Regresi

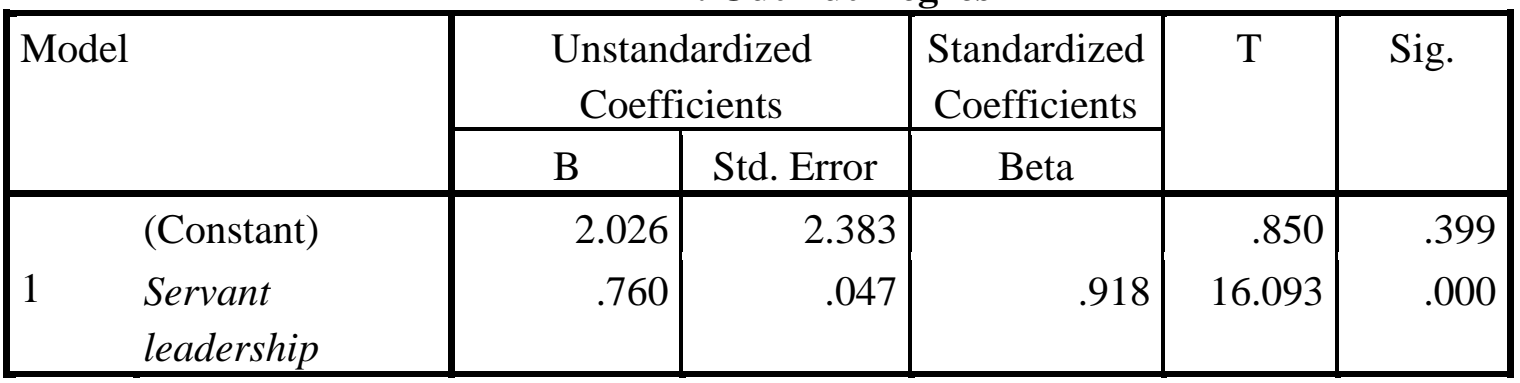

a. Dependent Variable: Kinerja

Berdasarkan out put regresi, maka persamaan regresi berganda dapat dikemukakan sebagai berikut:

$$
\mathrm{Y}=\mathbf{2 , 0 2 6}+\mathbf{0 , 7 6 0 X}+\mathrm{e}
$$

Pada Tabel 7 diatas diperoleh hasil uji anova dengan nilai untuk variabel servant leadership adalah 2,026 dengan signifikansi pada tingkat 0,000. Karena 0,000 < 0,05, maka $\mathrm{H}_{0}$ ditolak. Dengan demikian hipotesis servant leadership mempunyai pengaruh yang positif dan signifikan terhadap kinerja karyawan dapat dikonfirmasikan 


\subsection{Koefisien Determinasi}

Tabel 8. Koefisien Determinasi

\begin{tabular}{|c|c|}
\hline $\mathrm{R}$ & $R$ Square \\
\hline .918 & .844 \\
\hline
\end{tabular}

Berdasarkan hasil penghitungan diatas dapat diketahui bahwa koefisien determinasi adalah sebesar $84,4 \%$. Hal ini berarti bahwa variasi atau perubahan pada kinerja karyawan dapat dijelaskan sebesar $84,4 \%$ oleh perubahan servant leadership dan sisanya sebesar $15,6 \%$ dipengaruhi atau disebabkan oleh faktor lain yang tidak diteliti dalam kajian ini.

\section{DISKUSI DAN KETERBATASAN}

Hasil penelitian menunjukkan bahwa servant leadership mempunyai pengaruh positif dan signifikan terhadap kinerja, sehingga makin baik penerapan servant leadership maka kinerja yang dicapai akan makin baik. Hal ini sejalan dengan hasil penelitian yang dilakukan oleh Awan et al., (2012) Harwiki (2013), dan Koesmono (2014).

Dalam penelitian ini, pengaruh servant leadership terhadap kinerja karyawan, dari hasil koefisien determinasi (R Square) sebesar 0,844 yang berarti bahwa 84,4\% kinerja dapat dipengaruhi oleh variabel independen (servant leadership,. sisanya sebesar 15,6\% menunjukkan bahwa masih ada faktor-faktor atau variabel-varibel lain yang tidak diteliti dalam penelitian ini. Hal ini disebabkan karena masih banyak faktor atau variabel lainnya yang juga dapat mempengaruhi kinerja karyawan. Faktor-faktor tersebut antara lain disiplin kerja dan kepuasan kerja. Menurut Bacal dalam Fahmi (2011:29) disiplin kerja adalah sebuah proses yang digunakan untuk menghadapi permasalahan kinerja; proses ini melibatkan manajer dalam mengidentifikasi dan mengkomunikasikan masalah-masalah kinerja kepada karyawan. Hal ini sejalan dengan hasil penelitian Febiningtyas dan Ekaningtyas (2014) yang menyatakan bahwa disiplin berpengaruh positif dan signifikan terhadap kinerja. Sementara itu kepuasan kerja adalah perasaan positif tentang pekerjaan sebagai hasil evaluasi karakter-karakter pekerjaan itu (Robins dan Judge, 2009:40) 


\section{DAFTAR PUSTAKA}

Awan, Khuram Zafar., Ibnu-E-Waleed Qureshi., and Sadiya Arif. 2012. The Effective Leadership Style NGOs: Impact of Servant leadership Style on Employees' Work Motivation. International Journal of Economics and Management Sciences, vol.1, pp. 43-46.

Fahmi, Irham. 2011. Manajemen Kinerja Teori dan Aplikasi. Bandung: Alfabeta.

Harwiki, Wiwiek. 2013. Influence of Servant leadership to Motivation, Organization Culture, Organization Citizenship Behavior (OCB) and Employee's performance in Out Standing Cooperativee East Java Province,Indonesia. Journal of Business and Management, vol. 8, pp. 50-58.

Khan, Alamdar Hussain., Muhammad Mussarat Nawaz., and Muhammad Aleem., Wasim Hamed. 2012. Impact of Job Satisfaction on Employee Performance: An empirical Study of Autonomous Medical Institutitions of Pakistan. African Journal of Business Management, pp. 2697-2705.

Koesmono, Teman H. 2014. The Influence of Organizational Culture, Servant leadership, and Job Satisfaction to Ward Organizational Commitment and Job Performance Through Work Motivation as Moderating variables for Lecturers in Economic and Management of Private Universities in East Surabaya. Educational Reseacrh International. Vol. 3(4).

Lisbijanto, Herry., and Budiyanto. 2014. Influence of Servant leadership on Organization Performance Through Job Satisfaction in Employees' Cooperative Surabaya. International Journal of Business and Management Invention, vol. 3, pp. 03-06.

Mas'ud, Fuad. 2004. Survai Diagnosis Organisasional Konsep \& Aplikasi. Badan Penerbit Undip.

Moeheriono. 2009. Pengukuran Kinerja Berbasis Kompetensi. Bogor: Ghalia Indonesia. 2014. Pengukuran Kinerja Berbasis Kompetensi. Jakarta: Raja Grafindo Persada.

Northouse, Peter G. 2013. Kepemimpinan. Jakarta: PT. Index

Priyatno. 2014. SPSS 22 Pengolah Data Terpraktis. Yogyakarta: Andi.

Robins, Stephen P., and Timothy A, Judge. 2009. Perilaku Organisasi. Alih Bahasa oleh Benyamin Rolan. Jakarta: Salemba Empat.

Sedarmayanti. 2014. Manajemen Sumber Daya Manusia. Bandung: Refika Aditama.

Setiawan, Ivan, A., dan Ferdiansyah Ritonga. 2011. Analisis Jalur Dengan Program AMOS. Tamheramh: Suluh Media.

Silalahi, Ulber. 2013.Asas-Asas Manajemen. Bandung: Rafika Aditama.

Siregar, Sofyan. 2013. Metode Penelitian Kuantitatif. Jakarta: Kencana Prenada Media Group 
Sudarmanto. 2014. Kinerja dan Pengembangan Potensi SDM Teori, Dimensi, Pengukuran, dan Implementasi dalam Organisasi. Yogyakarta: Pustaka Pelajar.

Sugiyono. 2009. Metode Penelitian Kuantitatif, Kualitatif dan R\&D. Bandung: Alfabeta . 2013. Metode Penelitian Bisnis. Bandung: Alfabeta.

Tehseen, Shehnaz., and Noor U1 Hadi. 2015. Factor Influencing Teachers' Performance and Retention. Mediterranean Journal of Social Sciences.

Wirawan. 2012. Evaluasi Kinerja Sumber Daya Manusia Teori, Aplikasi, dan Penelitian. Jakarta: Salemba Empat.

Yukl, Gary. 2005. Kepemimpinan Dalam Organisasi. Alih Bahasa oleh Budi Supriyanto. PT. Index. 